\title{
ANALISIS STRATEGI PEMASARAN TERKAIT KEPUTUSAN PEMBELIAN KONSUMEN PADA PRODUK AKFIX
}

\author{
Wilson Anthony Chandra \\ Program Studi Magister Manajemen Universitas Tarumanagara \\ Wilsonanthonychandra@gmail.com
}

\begin{abstract}
This study aims to analyze marketing strategies related to consumer purchasing decisions on Akfix products. In this research data collection method used is questionnaire to know the factors sought by customer in choosing product of Akfix. The sample is 100 respondents who purchase Akfix products. Data analysis method used is regression analysis and SWOT. Based on the result of the research, it is concluded that evaluation of marketing strategy applied to current product of akfix is product has average value 4.04. This means that respondents agree with the statement that respondents buy Akfix products because they already recognize the problems I am facing, respondents buy Akfix products after collecting various information, respondents buy Akfix products after evaluating various alternatives, and respondents feel satisfied after buying and using Akfix products. Factors influencing purchasing decisions are product, promotion price, and distribution. This is obtained because based on the results of analysis using SPSS, proved all variables have a significance value below 0.005 . Product, promotion and distribution has a significance value of 0.000 while the price has naiai significance of 0.014 . The most appropriate strategy to increase product sales akfix is the product. This is obtained because based on the results of analysis using SPSS, proved that the product variable has the largest beta value among other variables that is equal to 0.414 .
\end{abstract}

Keywords: purchase decision, product, promotion price, distribution, SWOT

\section{PENDAHULUAN}

Keputusan pembelian adalah tindakan yang dilakukan konsumen untuk melakukan pembelian sebuah produk. Oleh karena itu, pengambilan keputusan pembelian konsumen merupakan suatu proses pemilihan salah satu dari beberapa alternatif penyelesaian masalah dengan tindak lanjut yang nyata. Setelah itu konsumen dapat melakukan evaluasi pilihan dan kemudian dapat menentukan sikap yang akan diambil selanjutnya. Dalam sebuah keputusan pembelian terdapat beberapa peran konsumen yaitu inisiator, influencer, decider, buyer, user. Perusahaan perlu mengenal peranan tersebut karena semua peranan mengandung implikasi guna merancang produk, menentukan pesan dan mengalokasikan biaya anggaran promosi serta membuat program pemasaran yang sesuai dengan pembeli (Swastha dan Handoko, 2011). Terdapat empat faktor yang mempengaruhi perilaku keputusan pembelian konsumen yaitu budaya, sosial, pribadi dan psikologis (Kotler, 2003:202).

Pada penelitian ini akan difokuskan pada Produk Akfix PU Sealant p635 600ml. Produk ini dijual dengan harga Rp 54.000, adapun pesaingnya adalah produk Sika 600ml dengan harga $\mathrm{Rp}$ 98.000. Produk akfix adalah sealant yang dapat digunakan di area luar dan dalam bangunan yang dapat digunakan untuk sambungan-sambungan pada bidang horisontal dan vertikal. Produk akfix juga dapat menahan pergerakan sambungan yang ekstrim dengan elastisitas yang sempurna.

Akfix adalah sealant yang dapat digunakan di area luar dan dalam bangunan. Waterproof. Produk ini dapat digunakan untuk sambungan-sambungan pada bidang 
horisontal dan vertikal, dapat menahan pergerakan sambungan yang ekstrim dengan elastisitas yang sempurna, berdaya rekat tinggi pada hampir semua permukaan, tidak membutuhkan lapisan primer, tidak bergelembung (bubble), dan dapat diaplikasikan pada permukaan basah dan lembab, dapat dicat, tidak susut dan tahan terhadap sinar UV, tidak melorot pada waktu diaplikasikan. Slump resistance. Produk ini juga aman buat lingkungan (Environmental friendliness). cepat kering dan tahan terhadap panas (Heat resistance), tidak menangkap debu/kotoran dan tidak menimbulkan noda pada material yang disealant.

Hasil penelitian Simbolon (2013) juga menyatakan bahwa strategi produk berpengaruh terhadap keputusan pembelian konsumen, jadi semakin baik strategi produk diterapkan maka akan meningkatkan keputusan pembelian konsumen. Penelitian terdahulu yang dilakukan oleh Hasan et al (2016) menyimpulkan bahwa ada pengaruh marketing mix seperti produk, promosi, lokasi, karyawan, infrastruktur, proses pelayanan terhadap keputusan pembelian konsumen. Penelitian lain yang dilakukan oleh Andreti et al (2013) menyimpulkan bahwa produk, harga, promosi dan pelayanan serta lokasi berpengaruh signifikan terhadap keputusan pembelian konsumen.

Indumathi dan Dawood (2016) mengidentifikasi faktor terpenting bagi konsumen adalah harga, produk, dan faktor promosi. Faktor produk agak lebih penting bagi pelanggan diikuti oleh kualitas, brand, kesehatan dan keamanan lingkungan dan rasa. Faktor tempat tidak sangat penting bagi konsumen dibandingkan dengan faktor produk. Kenyamanan adalah yang paling faktor penting di tempat. Faktor harga yang dipertimbangkan adalah biaya tinggi, harga terjangkau danuntuk kualitas Orang-orang menerima harga kesehatan demi kesehatan. Konsumen adalahmengharapkan produk tersebut dikirimkan ke rumah. Studi ini akan berguna untuk toko produk organik di Chennai. Identifikasi dari faktor akan membantu pemilik toko untuk menyesuaikan strategi pemasaran dan manufaktur merekauntuk memanfaatkan pengaruh ini dengan cara yang akan memuaskan konsumen dan pemasar Mereka dapat merumuskan strategi dan membantu pengembangan toko dan petani.

Pada penelitian ini akan membahas tentang analisis bisnis yang ada pada produk akfix, khususnya untuk menganalisis strategi pemasaran yang selama ini dilakukan oleh perusahaan, faktor-faktor yang mempengaruhinya, serta strategi dimasa mendatang untuk meningkatkan keputusan pembelian konsumen.

\section{TINJAUAN PUSTAKA Produk}

Produk merupakan segala sesuatu yang dapat ditawarkan produsen untuk diperhatikan, diminta, dicari, dibeli, digunakan, atau dikonsumsi pasar sebagai pemenuhan kebutuhan atau keinginan pasar yang bersangkutan. Secara konseptual produk adalah pemahaman subyektif dari produsen atas sesuatu yang bisa ditawarkan, sebagai usaha untuk mencapai tujuan organisasi melalui pemenuhan kebutuhan dan keinginan konsumen, sesuai dengan kompetensi dan kapasitas organisasi serta daya beli pasar (Tjiptono, 2010). Produk adalah segala sesuatu yang dapat ditawarkan ke pasar untuk diperhatikan ,dimiliki, digunakan ,atau dikonsumsi yang dapat memuaskan keinginan dan kebutuhan. Produk mencakup objek fisik, jasa, orang, tempat, organisasi dan gagasan.

\section{Price (Harga)}

Kotler dan Amstrong (2012) mendefinisikan harga sebagai sejumlah uang yang dibayarkan atas barang dan jasa atau jumlah nilai yang konsumen tukarkan dalam rangka mendapatkan manfaat dari memiliki atau menggunakan barang dan jasa. Harga terbukti menjadi faktor yang cukup besar mempengaruhi pembeli dalam memilih produk. Menurut Augusty Ferdinand (2013), harga merupakan salah satu variabel penting dalam pemasaran, di 
mana harga dapat mempengaruhi konsumen dalam mengambil keputusan untuk membeli suatu produk, karena berbagai alasan.

\section{Place (Distribusi/Lokasi)}

Lokasi adalah tempat perusahaan beroperasi atau tempat perusahaan melakukan kegiatan untuk menghasilkan barang dan jasa yang mementingkan segi ekonominya (Fandy Tjiptono,2010:92). Kotler dan Armstrong (2012:76) mejelaskan bahwa lokasi juga meliputi kegiatan perusahaan yang membuat produknya tersedia untuk pelanggan sasaran.Lupiyoadi (2009) mendefinisikan lokasi sebagai tempat dimana perusahaan harus bermarkas melakukan operasi.

\section{Promosi}

Aktivitas promosi merupakan usaha marketing yang menberikan berbagai upaya intensif jangka pendek untuk mendorong keinginan mencoba atau membeli suatu produk atau jasa (Kotler dan Armstrong,2012:76).Rambat Lupiayoadi (2010: 120) mengatakan bahwa kegiatan promosi bukan saja berfungsi sebagai alat komunikasi antara perusahaan dengan konsumen dalam kegiatan pembelian atau penggunaan jasa sesuai dengan keinginan dan kebutuhannya. Kotler dan Armstrong (2012:448) mengemukakan bahawa konsep dari mengkomunikasikan pemasaran berada pada alat promosi yang terkoordinasi melalui promotion mix. Setiap alat promosi memiliki karakteristik yang unik dan biaya tersendiri.

\section{Analisis SWOT}

Suatu bisnis dikatakan bisnis yang baik jika bisnis tersebut memiliki strategi yang baik dalam menjalankan usahanya. Analisis SWOT adalah identifikasi berbagai faktor secara sistematis untuk merumuskan strategi perusahaan. Analisis ini didasarkan pada logika yang dapat memaksimalkan kekuatan (Strengths) dan peluang (Opportunities), namun secara bersamaan dapat meminimalkan kelemahan (Weaknesses) dan ancaman (Threats). Proses pengambilan keputusan strategis selalu berkaitan dengan pengembangan misi, tujuan, strategi, dan kebijakan perusahaan. Dengan demikian perencanaan strategis (strategic planner) harus menganalisis faktor-faktor strategis perusahaan (kekuatan, kelemahan, peluang, dan ancaman) dalam kondisi yang ada saat ini. SWOT adalah singkatan dari lingkungan Internal Strengths dan Weaknesses serta lingkungan Eksternal Opportunities dan Threats yang dihadapi dalam suatu bisnis.

\section{Keputusan pembelian konsumen}

Suatu keputusan dapat dibuat hanya jika ada beberapa alternatif yang dipilih. Apabila alternatif pilihan tidak ada maka tindakan yang dilakukan tanpa adanya pilihan tersebut tidak dapat dikatakan membuat keputusan. Menurut Kotler dan Armstrong (2008:181), keputusan pembelian konsumen adalah membeli merek yang paling disukai dari berbagai alternatif yang ada, tetapi dua faktor bisa berada antara niat pembelian dan keputusan pembelian. Faktor pertama adalah sikap orang lain dan faktor yang kedua adalah faktor situasional. Oleh karena itu, preferensi dan niat pembelian tidak selalu menghasilkan pembelian yang aktual. Pengambilan keputusan merupakan suatu kegiatan individu yang secara langsung terlibat dalam mendapatkan dan mempergunakan barang yang ditawarkan. Menurut Setiadi, (2003:341), mendefinisikan suatu keputusan (decision) melibatkan pilihan diantara dua atau lebih alternatif tindakan atau perilaku. 


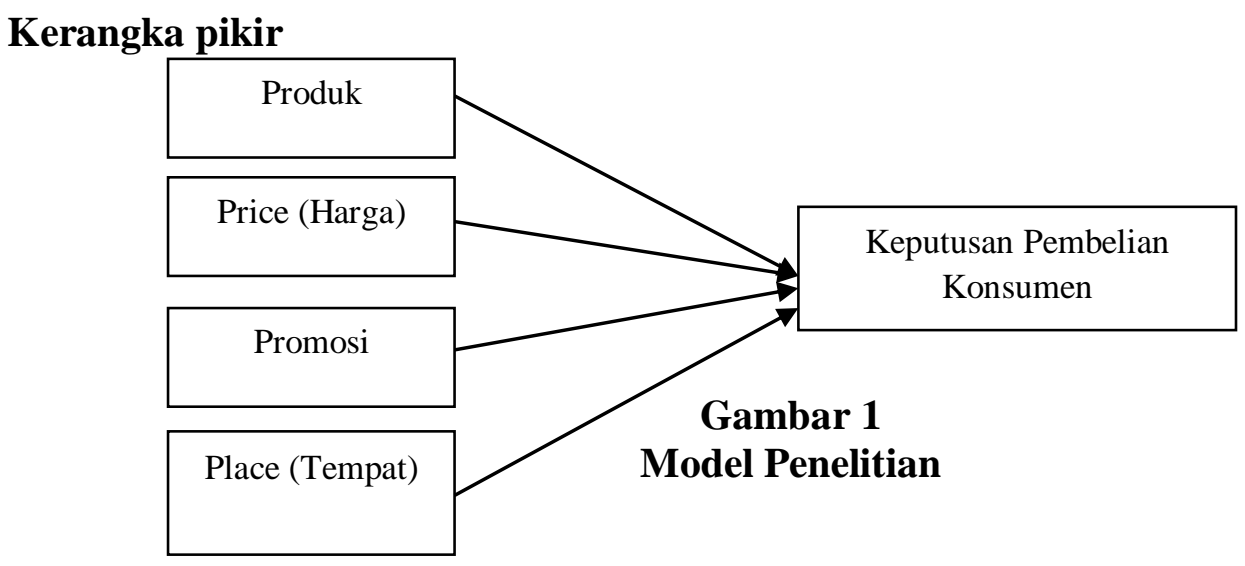

\section{Hipotesis}

H1: Produk berpengaruh terhadap keputusan pembelian konsumen.

H2: Price (Harga) berpengaruh terhadap keputusan pembelian konsumen.

H3: Promosi berpengaruh terhadap keputusan pembelian konsumen.

H4: Place (Tempat) berpengaruh terhadap keputusan pembelian konsumen.

\section{ANALISIS DAN PEMBAHASAN}

Penelitian ini menggunakan metode kuantitatif. Analisis yang digunakan yaitu analisis regresi linear berganda. Jumlah responden yang diambil adalah sebanyak 100 responden yang membeli produk Akfix. Data sekunder dalam penelitian ini adalah hasil proses data kuesioner melalui SPSS 22 for Windows. Selain itu, dilakukan pencarian informasi mengenai produk kompetitor serta dilakukan analisis Porter 5 Forces dan SWOT pada data yang telah dikumpulkan.

\section{ANALISIS REGRESI LINEAR BERGANDA} berikut:

Pada penelitian ini menggunakan analisis regresi linear berganda dengan hasil sebagai

Tabel 1. Analisis Regresi Linear Berganda

\section{Coefficients $^{\mathrm{a}}$}

\begin{tabular}{|c|c|c|c|c|c|c|}
\hline \multirow{2}{*}{\multicolumn{2}{|c|}{ Model }} & \multicolumn{2}{|c|}{$\begin{array}{c}\text { Unstandardized } \\
\text { Coefficients } \\
\end{array}$} & \multirow{2}{*}{$\begin{array}{c}\begin{array}{c}\text { Standardized } \\
\text { Coefficients }\end{array} \\
\text { Beta }\end{array}$} & \multirow[b]{2}{*}{$\mathrm{t}$} & \multirow[b]{2}{*}{ Sig. } \\
\hline & & $\mathrm{B}$ & Std. Error & & & \\
\hline \multirow[t]{5}{*}{1} & (Constant) & $-2,632$ & 1,020 & & $-2,581$ & 011 \\
\hline & produk & ,414 & ,056 & ,417 & 7,396 &, 000 \\
\hline & harga & , 158 & ,063 & , 156 & 2,516 &, 014 \\
\hline & promosi & ,201 &, 046 & ,257 & 4,408 & ,000 \\
\hline & distribusi & ,402 &, 074 & ,307 & 5,458 &, 000 \\
\hline
\end{tabular}

a. Dependent Variable: keputusan_pembelian

Sumber: Data Primer yang Diolah (2018)

Persamaan regresi:

$\mathrm{Y}=-2,632+0,414 \mathrm{X} 1+0,158 \mathrm{X} 2+0,201 \mathrm{X} 3-0,402 \mathrm{X} 4$

Dimana:

$\mathrm{Y}=$ Keputusan Pembelian 


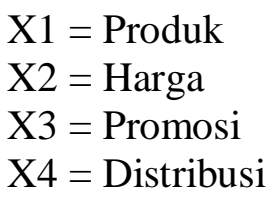

Koefisien Determinasi $\left(\mathbf{R}^{2}\right)$

Tabel 2. Hasil Uji Koefisien Determinasi $\left(\mathbf{R}^{2}\right)$

Model Summary ${ }^{b}$

\begin{tabular}{|l|c|r|r|r|r|}
\hline Model & R & R Square & $\begin{array}{c}\text { Adjusted R } \\
\text { Square }\end{array}$ & $\begin{array}{c}\text { Std. Error of } \\
\text { the Estimate }\end{array}$ & $\begin{array}{c}\text { Durbin- } \\
\text { Watson }\end{array}$ \\
\hline 1 &, $900^{\mathrm{a}}$ &, 809 &, 801 & 1,22718 & 1,771 \\
\hline
\end{tabular}

a. Predictors: (Constant), distribusi, promosi, produk, harga

b. Dependent Variable: keputusan_pembelian

Sumber: Data Primer yang Diolah (2018)

Berdasarkan pada tabel tersebut diketahui bahwa adjusted R Square sebesar 0,801 yang artinya variabel independen dapat mempengaruhi variabel dependen sebesar $80,1 \%$ dan sisanya sebesar 19,9\% dipengaruhi oleh variabel lainnya.

Uji F

Tabel 3. Hasil Uji F

ANOVA ${ }^{\mathrm{a}}$

\begin{tabular}{|ll|r|r|r|r|r|}
\hline \multicolumn{2}{|l|}{ Model } & $\begin{array}{c}\text { Sum of } \\
\text { Squares }\end{array}$ & df & Mean Square & F & Sig. \\
\hline 1 & Regression & 606,642 & 4 & 151,660 & 100,706 &, $000^{\mathrm{b}}$ \\
& Residual & 143,068 & 95 & 1,506 & & \\
& Total & 749,710 & 99 & & & \\
\hline
\end{tabular}

a. Dependent Variable: keputusan_pembelian

b. Predictors: (Constant), distribusi, promosi, produk, harga

Sumber: Data Primer yang Diolah (2018)

Berdasarkan pada tabel tersebut diketahui bahwa nilai sig.F sebesar $0.000<0.05$ yang artinya model fit. Jadi variabel independen dapat digunakan untuk memprediksi variabel dependen.

Uji t

\section{Pengujian Hipotesis Pertama}

Hipotesis pertama pada penelitian ini adalah produk berpengaruh terhadap keputusan pembelian konsumen pada Produk Akfix. Berdasarkan pada tabel tersebut diperoleh nilai signifikansi t untuk variabel produk sebesar 0,000 yang nilainya $<0,05$ dengan nilai koefisien regresi sebesar $+0,414$. Artinya strategi produk berpengaruh positif terhadap keputusan pembelian konsumen pada Produk Akfix. Jadi hipotesis pertama diterima.

\section{Pengujian Hipotesis Kedua}

Hipotesis kedua pada penelitian ini harga berpengaruh terhadap keputusan pembelian konsumen pada Produk Akfix. Berdasarkan pada tabel tersebut diperoleh nilai signifikansi t untuk variabel harga sebesar 0,014 yang nilainya $<0,05$ dengan nilai koefisien regresi sebesar $+0,158$. Artinya harga berpengaruh positif terhadap keputusan pembelian konsumen pada Produk Akfix. Jadi hipotesis kedua diterima.

\section{Hipotesis Ketiga}

Hipotesis ketiga pada penelitian ini adalah promosi berpengaruh terhadap keputusan pembelian konsumen pada Produk Akfix. Berdasarkan pada tabel tersebut diperoleh nilai 
signifikansi t untuk variabel promosi sebesar 0,000 yang nilainya > 0.05 dengan nilai koefisien regresi sebesar $+0,201$. Artinya promosi berpengaruh positif terhadap keputusan pembelian konsumen pada Produk Akfix. Jadi hipotesis ketiga diterima.

\section{Hipotesis Keempat}

Hipotesis keempat pada penelitian ini adalah distribusi berpengaruh terhadap keputusan pembelian konsumen pada Produk Akfix. Berdasarkan pada tabel tersebut diperoleh nilai signifikansi $t$ untuk variabel distribusi sebesar 0,000 yang nilainya $<0,05$ dengan nilai koefisien regresi sebesar $+0,402$. Artinya distribusi berpengaruh posirif terhadap keputusan pembelian konsumen pada Produk Akfix. Jadi hipotesis keempat diterima.

\section{Analisis SWOT}

Berikut ini adalah tabel analisis SWOT pada Produk Akfix: 
Tabel 4. SWOT Matriks

\begin{tabular}{|c|c|c|}
\hline Always Leave Blank & $\begin{array}{l}\text { S (Strengh)-Kekuatan: } \\
\text { 1. Produk Akfix sudah memenuhi } \\
\text { harapan konsumen (kualitas } \\
\text { produk baik) } \\
\text { 2. Selama ini produk Akfix } \\
\text { memiliki agen penjualan yang } \\
\text { strategis }\end{array}$ & $\begin{array}{l}\text { W (Weakness) - Kelemahan: } \\
\text { 1. Produk Akfix selama ini } \\
\text { memiliki saluran distribusi } \\
\text { kurang memadai } \\
\text { 2. Promosi produk Aktif masih } \\
\text { kurang }\end{array}$ \\
\hline 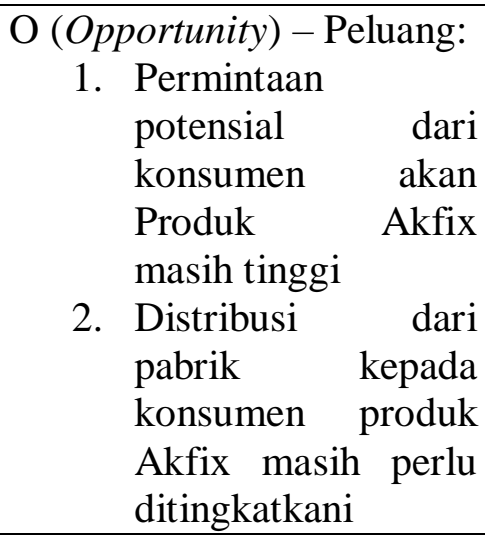 & $\begin{array}{l}\text { SO Strategies: } \\
\text { 1. Produk Akfix memiliki } \\
\text { permintaan yang tinggi dan sudah } \\
\text { memenuhi harapan konsumen } \\
(\mathrm{O} 1, \mathrm{~S} 1) \\
\text { 2. Meningkatkan distribusi dari } \\
\text { pabrik kepada konsumen produk } \\
\text { Akfix agar memiliki agen } \\
\text { penjualan yang strategis }(\mathrm{O} 2, \mathrm{~S} 2)\end{array}$ & $\begin{array}{l}\text { WO Strategies: } \\
\text { 1. Produk Akfix memiliki } \\
\text { permintaan konsumen yang tinggi } \\
\text { maka perlu untuk meningkatkan } \\
\text { saluran distribusiya }(\mathrm{O} 1, \mathrm{~W} 1) \\
\text { 2. Menambah promosi untuk } \\
\text { meningkatkan distribusi dari } \\
\text { pabrik kepada konsumen produk } \\
\text { Akfix }(\mathrm{O} 1, \mathrm{~W} 2)\end{array}$ \\
\hline $\begin{array}{l}\text { T (Threats) - Ancaman: } \\
\text { 1. Banyaknya pesaing } \\
\text { di bidang yang } \\
\text { sama } \\
\text { 2. Ancaman tawaran } \\
\text { harga pesaing yang } \\
\text { lebih murah } \\
\text { merupakan masalah } \\
\text { bagi produk Akfix }\end{array}$ & $\begin{array}{l}\text { ST Strategies: } \\
\text { 1.Memenuhi harapan konsumen } \\
\text { untuk mengatasi persaingan yang } \\
\text { ada (T1,S1) } \\
2 . \quad \text { Menghadapi ancaman } \\
\text { persaingan harga dengan memiliki } \\
\text { agen penjualan yang strategis (T2, } \\
\text { S2) }\end{array}$ & $\begin{array}{l}\text { WT Strategies: } \\
\text { 1. Memiliki saluran distribusi agar } \\
\text { dapat menghadapi pesaingan (W1, } \\
\text { T1) } \\
\text { 2. Dalam menghadapi persaingan } \\
\text { harga harus melakukan promosi } \\
\text { yang lebih (W3, T1) }\end{array}$ \\
\hline
\end{tabular}

\section{PEMBAHASAN}

\section{Evaluasi strategi pemasaran yang diterapkan pada produk akfix saat ini}

Berdasarkan hasil analisis diketahui bahwa produk memiliki nilai rata-rata 4,04. Artinya reponden setuju dengan pernyataan yang menyatakan bahwa responden membeli produk Akfix karena sudah mengenali masalah yang saya hadapi, responden membeli produk Akfix setelah mengumpulkan berbagai informasi, responden membeli produk Akfix setelah melakukan evaluasi berbagai alternatif, dan responden merasa puas setelah membeli dan menggunakan produk Akfix.

Untuk variabel harga memiliki nilai rata-rata 3,88. Artinya reponden setuju dengan pernyataan yang menyatakan bahwa produk Akfix memiliki kualitas produk yang baik, sudah memenuhi harapan konsumen dan memiliki desain yang baik, memiliki merk yang cukup terkenal, dan memiliki kinerja yang baik. Untuk variabel promosi memiliki nilai rata-rata 3,97. Artinya reponden setuju dengan pernyataan yang menyatakan bahwa produk Akfix memberikan potongan harga kepada konsumennya, memiliki penetapan harga yang baik, memiliki variasi berbagai pilihan tipe, dan harga Produk Akfix lebih murah dibandingkan pesaingnya.

Untuk variabel distribusi memiliki nilai rata-rata 4,19. Artinya reponden setuju dengan pernyataan yang menyatakan bahwa promosi produk Akfix dilakukan dengan iklan di media sosial, promosi iklan Produk Akfix di spanduk, baleho, poster menarik minat saya untuk membeli, tampilan iklan Produk Akfix menarik minat konsumen untuk membelinya, 
dan promosi produk Aktif dilakukan dengan cukup intens melalui promosi penjualan, bosus, hadiah langsung. Untuk variabel keputusan pembelian memiliki nilai rata-rata 4,02. Artinya reponden setuju dengan pernyataan yang menyatakan bahwa distribusi produk Akfix selama ini tersebar luas sehingga mudah untuk mendapatkannya, selama ini produk Akfix memiliki agen penjualan yang strategis,distribusi dari pabrik kepada konsumen produk Akfix ini mudah dijangkau, dan produk Akfix selama ini memiliki saluran distribusi yang memadai.

\section{Faktor-faktor yang mempengaruhi keputusan pembelian konsumen produk akfix}

Faktor faktor yang mempengaruhi keputusan pemeblian adalah produk, harga promosi, dan distribusi. Hal ini didapat karena berdasarkan hasil analisis menggunakan SPSS, terbukti semua variabel memiliki nilai signifikansi dibawah 0,005. Produk, promosi dan distribusi memiliki nilai signifikansi 0,000 sedangkan harga memiliki nikai signifikansi 0,014.

\section{Strategi yang paling tepat untuk meningkatkan penjualan produk akfix}

Strategi yang paling tepat untuk meningkatkan penjualan produk akfix adalah produk. Hal ini didapat karena berdasarkan hasil analisis menggunakan SPSS, terbukti bahwa variabel produk memiliki nilai beta paling besar diantara variabel yang lain yaitu sebesar 0,414. Produk merupakan segala sesuatu yang dapat ditawarkan produsen untuk diperhatikan, diminta, dicari, dibeli, digunakan, atau dikonsumsi pasar sebagai pemenuhan kebutuhan atau keinginan pasar yang bersangkutan. Suatu produk mungkin diminati karena lebih mudah dipakai, lebih efektif atau lebih awet. Keunggulan kompetitif apapun dari suatu produk ini dengan produk sejenis dari pesaing harus dijelaskan. Dapat disimpulkan bahwa produk adalah seperangkat atribut baik yang berwujud maupun tidak berwujud yang digunakan untuk memenuhi kebutuhan konsumen

\section{KESIMPULAN}

Berdasarkan hasil penelitian, dapat disimpulkan bahwa Evaluasi strategi pemasaran yang diterapkan pada produk akfix saat ini adalah produk memiliki nilai rata-rata 4,04. Artinya reponden setuju dengan pernyataan yang menyatakan bahwa responden membeli produk Akfix karena sudah mengenali masalah yang saya hadapi, responden membeli produk Akfix setelah mengumpulkan berbagai informasi, responden membeli produk Akfix setelah melakukan evaluasi berbagai alternatif, dan responden merasa puas setelah membeli dan menggunakan produk Akfix.

Faktor faktor yang mempengaruhi keputusan pembelian adalah produk, harga promosi, dan distribusi. Hal ini didapat karena berdasarkan hasil analisis menggunakan SPSS, terbukti semua variabel memiliki nilai signifikansi dibawah 0,005. Produk, promosi dan distribusi memiliki nilai signifikansi 0,000 sedangkan harga memiliki nikai signifikansi 0,014 .

Strategi yang paling tepat untuk meningkatkan penjualan produk akfix adalah produk. Hal ini didapat karena berdasarkan hasil analisis menggunakan SPSS, terbukti bahwa variabel produk memiliki nilai beta paling besar diantara variabel yang lain yaitu sebesar 0,414.

Saran untuk penelitian ini adalah Sebaiknya perusahaan dapat meningkatkan produk, harga promosi, dan distribusi, karena berdasarkan hasil penelitian terbukti bahwa keempat variabel tersebut mempengaruhi keputusan pemelian produk Akfix. Untuk penelitian yang mendatang sebaiknya menambahkan variabel yang mempengaruhi keputusan pembelian konsumen serta menambahksan sampel penelitian. 


\section{DAFTAR PUSTAKA}

Assauri, Sofyan. 2002. Manajemen Pemasaran, dasar, konsep, dan strategi. Cetakan Ketiga, Jakarta : CV. Rajawali.

Ghozali, Imam. 2013. Aplikasi Analisis Multivariate Dengan Program SPSS. Semarang: Badan Penerbit Universitas Diponegoro.

Kotler, Philip And Gary Armstrong. 2012. Prinsip-Prinsip Pemasaran. Edisi. 13. Jilid 1. Jakarta: Erlangga.

Kotler, Philip dan Kevin Lane Keller. 2009. Manajemen Pemasaran. Edisi 13 Jilid Satu. Jakarta: Erlangga.

Lupiyoadi, R. dan Hamdani, A. 2010. Manajemen Pemasaran Jasa. Jakarta: Salemba Empat.

Simbolon dan Marhayanie. 2013. Pengaruh Strategi Bauran Pemasaran Terhadap Keputusan Pembelian Kartu Simpati Telkomsel Pada Mahasiswa Fakultas Ekonomi Program S1 Universitas Sumatera Utara. Jurnal Ekonomi dan Bisnis.

Sugiyono. 2013. Metode Penelitian Pendidikan Pendekatan Kuantitatif, Kualitatif, dan R\&D. Bandung: Alfabeta.

Swastha, B., dan Hani Handoko. 2011. Manajemen Pemasaran-Analisis Perilaku Konsumen. Yogyakarta: BPFE. 


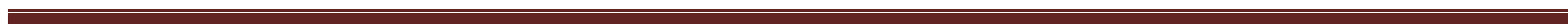
$\cdot$ 